\title{
TANNIN SENSITIVITY IN LARVAE OF Malacosoma disstria (LEPIDOPTERA): ROLES OF THE PERITROPHIC ENVELOPE AND MIDGUT OXIDATION
}

\author{
RAYMOND V. BARBEHENN AND MICHAEL M. MARTIN*
}

\author{
Department of Biology \\ University of Michigan \\ Ann Arbor, Michigan 48109-1048
}

(Received December 1, 1993; accepted March 28, 1994)

\begin{abstract}
Final-instar Malacosoma disstria fed artificial diets containing tannic acid develop lethal pupal deformities. We examined some of the factors potentially underlying tannin sensitivity in this species, including the permeability of the peritrophic envelope to tannic acid and the chemical fate of tannic acid in the gut. Tannic acid does not penetrate the peritrophic envelope of $M$. disstria, demonstrating that the containment of tannic acid within the endoperitrophic space is not sufficient to protect an insect herbivore from the adverse effects of ingested tannins. Ingested tannic acid undergoes extensive chemical modification in the midgut. Only $19-21 \%$ of the high molecular weight components of the tannic acid ingested was recovered in the frass. Of two possible chemical fates of ingested tannic acid, oxidation is the predominant chemical transformation, whereas little hydrolysis occurs. Measurements of gut redox parameters showed that conditions in the midgut favor the oxidation of phenols. However, similar conditions occur in the midguts of Orgyia leucostigma, in which no oxidation occurs. Therefore, oxidizing gut redox conditions do not necessarily lead to polyphenol oxidation in lepidopteran larvae. We conclude that the sensitivity of $M$. disstria to ingested tannins is a consequence of their oxidation in the midgut.
\end{abstract}

Key Words-Lepidoptera. Lasiocampidae, Malacosoma disstria, Orgyia leucostigma, larva, tannin, tannic acid, peritrophic membrane, oxidation.

\section{INTRODUCTION}

Insect herbivores vary greatly in their sensitivity to ingested tannins. In tanninsensitive species, low levels of dietary tannins can have a variety of adverse

* To whom correspondence should be addressed. 
consequences, ranging from reduced growth and abnormal development to death. Whereas at one time it was believed that the adverse effects of tannins resulted from their proclivity to bind with proteins in the gut and inhibit protein digestion (Feeny, 1976; Rhoades and Cates, 1976), it is now recognized that tannins and other polyphenols can act by a variety of different mechanisms in insects, including inhibition of feeding (Schultz, 1989; Hagerman and Butler, 1991), reduction in the efficiency of utilization of nutrients (Felton et al., 1989), and formation of lesions in the epithelial layer of the midgut (Bernays et al., 1980; Steinly and Berenbaum, 1985). It seems likely that in many cases the agent responsible for these effects is an oxidation product (e.g., a quinone) or a by-product of oxidation (e.g., superoxide anion radicals, hydroxyl radicals, or hydrogen peroxide) rather than the polyphenol itself (Appel and Martin, 1990; Appel, 1993).

Two factors are likely to be important in determining whether an insect will be adversely affected by ingested tannins: (1) the permeability of the peritrophic envelope (multiple layers of peritrophic membranes) to tannins or cytotoxic transformation products of tannins, and (2) the chemical conditions in the midgut that determine the chemical fate of ingested tannins.

We have recently reported a study of the permeability of the peritrophic envelope to tannic acid in tannin-tolerant larvae of the white-marked tussock moth, Orgyia leucostigma (Lymantriidae), and of the chemical fate of ingested tannic acid in this species (Barbehenn and Martin, 1992). We determined that in these larvae the peritrophic envelope is impermeable to tannic acid and that virtually all (90-100\%) ingested tannic acid is egested unchanged in the frass. Thus, tannin tolerance was associated with the effective containment of tannic acid within the endoperitrophic space and a lack of oxidation of tannic acid in the gut. In his seminal study of tannins and the oak moth, Operophtera brumata, Feeny (1970) also presented evidence suggesting that the peritrophic envelopes of $O$. brumata larvae are impermeable to tannins.

In the present study we have undertaken a similar exploration of the fate of ingested tannic acid in the tannin-sensitive larvae of the forest tent caterpillar, Malacosoma disstria (Lasiocampidae), a polyphagous tree-feeder (Stehr and Cook, 1968). Despite a wide host range that includes many tannin-producing trees (e.g., Quercus spp.), $M$. disstria larvae are highly sensitive to dietary tannins. When as little as $0.5 \%$ (dry weight) tannic acid is included in an artificial diet, early-instar larvae are unable to complete development, and larvae fed such a diet during the final instar develop lethal pupal deformities (Karowe, 1989). Like many oak-feeding Lepidoptera, this species feeds on its hosts during the time of leaf expansion, when tannins are present at their lowest levels (Feeny, 1968).

In this study, our experiments address the following questions: (1) Is the peritrophic envelope of $M$. disstria larvae permeable to tannic acid? (2) Is tannic acid chemically transformed during its passage through the gut? (3) If chemical 
transformation occurs, in what region(s) of the gut does this process take place? (4) By what process(es) are tannins chemically transformed? and (5) Are there differences in the redox conditions in the midguts of the tannin-sensitive larvae of $M$. disstria and the tannin-tolerant larvae of $O$. leucostigma?

\section{METHODS AND MATERIALS}

Insects and Diets. $M$. disstria and $O$. leucostigma eggs were obtained from the Forest Pest Management Institute (Sault Ste. Marie, Ontario). Larvae were reared at $22^{\circ} \mathrm{C}$ under a 16 -hr light-8-hr dark photoperiod at $70 \%$ average relative humidity, unless otherwise noted. $M$. disstria larvae were fed an artificial diet (Addy, 1969), modified by substituting $7.0 \mathrm{~g}$ of agar for sodium alginate and adding $4.0 \mathrm{~g}$ of methyl paraben (Sigma) per $605 \mathrm{~g}$ of dry diet. $O$. leucostigma larvae were reared on $O$. leucostigma diet (Bio-Serv Inc., Frenchtown, New Jersey) unless otherwise indicated.

Permeability of Peritrophic Envelope to Tannic Acid. Mid-fifth-instar (finalinstar) larvae $(N=11)$ were fed freshly prepared diet containing $3 \%$ dry wt tannic acid (Sigma lot No. 64F-0049) for two days. Intact guts were dissected from chilled $\left(-20^{\circ} \mathrm{C}, 7 \mathrm{~min}\right)$ larvae, the fore- and hindguts were ligated with silk sutures (size 6-0), and a small hole (average area $1.5 \mathrm{~mm}^{2} \pm 0.1 \mathrm{SE}$ ) was cut through the mid-midgut wall to expose the peritrophic envelope (Barbehenn and Martin, 1992). Dissected gut preparations were rinsed in three saline solutions ( $227 \mathrm{mM} \mathrm{KCl}, 3 \mathrm{mM} \mathrm{NaCl}, 300 \mathrm{mM}$ fructose, $\mathrm{pH} \mathrm{6.1)} \mathrm{for} 30-60 \mathrm{sec}$ and incubated in $2.0 \mathrm{ml}$ of the same solution in a shaker bath $\left(2 \mathrm{hr}, 23^{\circ} \mathrm{C}\right)$. Aliquots $(1.5 \mathrm{ml})$ of incubating solution were lyophilized, redissolved in 0.75 $\mathrm{ml}$ of mobile phase $(20 \%(\mathrm{v} / \mathrm{v})$ aqueous acetonitrile and $1 \%(\mathrm{v} / \mathrm{v})$ acetic acid) and filtered $(0.45 \mu \mathrm{m}$, Gelman Acrodisc). Tannic acid in these solutions was quantified using HPLC (10- $\mu \mathrm{l}$ injection; Waters $10-\mu \mathrm{m} \mathrm{C}-18$ column, $4.6 \times$ $250 \mathrm{~mm}$; flow rate $1.0 \mathrm{ml} / \mathrm{min}$; Shimadzu UV detector, $280 \mathrm{~nm}, 0.002 \mathrm{AU}$ ). Peak areas were integrated with a Shimadzu C-R4A Chromatopac. Control larvae fed a tannin-free diet $(N=3)$ were prepared similarly to determine the presence of interfering peaks in the HPLC chromatograms. The midgut contents of each larva were dried $\left(60^{\circ} \mathrm{C}\right.$, two days) and weighed to calculate the amount of tannic acid initially present in each midgut.

In a second test of the permeability of the peritrophic envelope to tannic acid, the above procedure was repeated with the following modifications: finalinstar larvae $(N=11)$ were fed artificial diet containing $8 \%$ (dry wt) tannic acid or control diet $(N=2)$, holes were cut through the anterior midgut wall, gut preparations were incubated in a $\mathrm{pH} 7.5$ buffered saline solution containing $3 \mathrm{mM}$ sodium chloride, $228 \mathrm{mM}$ potassium chloride, $41 \mathrm{mM}$ magnesium sulfate, $20 \mathrm{mM}$ calcium chloride, $52 \mathrm{mM}$ Tris (hydroxymethyl) aminomethane (Sigma), 
$7.5 \mathrm{mM}$ Tris(hydroxymethyl)aminomethane hydrochloride, and $440 \mathrm{mM}$ fructose, and 30- $\mu$ l samples were analyzed using HPLC.

Permeability of Peritrophic Envelope to Brown Pigments. The oxidation of tannins and other polyphenols produces brown pigments that can be quantified by measuring their absorbance at $420 \mathrm{~nm}$ (Cilliers and Singleton, 1989). We observed that brown pigments leached out of the fenestrated midguts of $M$. disstria that contained tannic acid. To quantify the amounts of brown pigments that permeated the peritrophic envelope, the incubating solutions from the second experiment described in the previous section (8\% tannic acid) were analyzed with HPLC as described above, with the exception that the absorbance of the eluate was measured at $420 \mathrm{~nm}$.

Tannic Acid Budget. Final-instar larvae $(N=13)$ were placed individually in 30-ml plastic cups with ventilated lids. Larvae were fed artificial diet containing 3\% (dry wt) tannic acid for three days, following which they were fed a tannin-free diet until all dark-colored (tannin-containing) frass had been collected. Larvae fed the tannin-free rearing diet $(N=4)$ served as controls to measure the presence of any substances in the frass that interfere with the measurement of egested tannic acid. Food and frass samples were collected daily, frozen $\left(-20^{\circ} \mathrm{C}\right)$, and lyophilized when the collection was completed. The amount of food consumed was calculated from the amount of frass produced and the approximate digestibility of the diet: (mg dry wt frass)/(1 - 0.555), where 0.555 is the value for the approximate digestibility (AD) for final-instar $M$. disstria larvae fed artificial diet containing $2 \%$ tannic acid (Karowe, 1989). The percent of ingested tannic acid remaining in the frass was calculated using the formula: (mg frass $\times \% \mathrm{TA}$ in frass)/(mg ingested diet $\times \% \mathrm{TA}$ in diet).

To prepare samples for tannic acid analysis, lyophilized samples (3-7 mg) of control diet $(N=3)$, frass from larvae fed the control diet $(N=4), 3 \%$ tannic acid diet $(N=4)$, and frass from larvae fed the tannin-containing diet $(N=13)$ were pulverized with a glass rod in screw-cap centrifuge tubes $(1.5$ $\mathrm{ml})$ and extracted in $70 \%$ acetone $\left(2 \times 1.0 \mathrm{ml}, 50^{\circ} \mathrm{C}, 45 \mathrm{~min}\right)$ in a shaker. Following centrifugation $(13,500 \mathrm{~g}, 15 \mathrm{~min})$, supernatant solutions were pooled within samples, concentrated to $1.0 \mathrm{ml}$ in a stream of nitrogen, lyophilized, redissolved in $1.0 \mathrm{ml}$ of $20 \%(\mathrm{v} / \mathrm{v})$ aqueous acetonitrile containing $1 \%(\mathrm{v} / \mathrm{v})$ acetic acid, and filtered $(0.45 \mu \mathrm{m})$. Filtered samples were analyzed by HPLC as described above. A tannic acid standard curve was constructed from a series of tannic acid solutions prepared by serial dilution. Artificial diet contained nontannin compounds that coeluted with the lower-molecular-weight components of tannic acid (peaks a and $\mathrm{b}$, Figure 1A below). In order to quantify higher-molecular-weight tannins (peaks $\mathrm{c}$ and d, Figure 1A below), areas of nontannin peaks (identified in control samples) with retention times greater than $4.0 \mathrm{~min}$ were subtracted from corresponding peak areas in chromatograms of extracts of tannin-containing samples. 
Tannic Acid Levels Along the Gut. We dissected samples of the contents of foreguts $(0.2-4.0 \mathrm{mg}$ dry $\mathrm{wt})$, anterior midguts $(0.8-1.4 \mathrm{mg} \mathrm{dry} \mathrm{wt})$, posterior midguts $(0.7-1.8 \mathrm{mg}$ dry $\mathrm{wt})$, and hindguts $(0.4-2.2 \mathrm{mg}$ dry $\mathrm{wt}$ ) of chilled $\left(-20^{\circ} \mathrm{C}, 7 \mathrm{~min}\right)$ larvae that had been fed either a diet containing $3 \%$ tannic acid $(N=11)$ or a tannin-free diet $(N=3)$. Fresh weight-to-dry weight conversion factors for foregut, midgut, and hindgut samples were calculated from control larvae. Samples of gut contents were extracted in $70 \%$ acetone $(1.0 \mathrm{ml})$ and centrifuged $(10,000 \mathrm{~g}, 10 \mathrm{~min})$. Supernatant solutions $(0.5 \mathrm{ml})$ were partially evaporated in a stream of nitrogen, lyophilized, redissolved in mobile phase $(1.0 \mathrm{ml})$, filtered $(0.45 \mu \mathrm{m})$, and the high-molecular-weight component $d$ was quantified using HPLC, as described above.

Gallic Acid Budgets. Two- to 3-day-old final-instar $M$. disstria larvae ( $N$ $=13$ ), reared at $22^{\circ}$ and $24^{\circ} \mathrm{C}$, were fed artificial diet containing $2 \%$ dry wt gallic acid (Sigma) for three days followed by gallic acid-free diet. Egested gallic acid was recovered by collecting all dark brown or black frass. Frass and diet samples were collected daily, frozen $\left(-20^{\circ} \mathrm{C}\right)$, and lyophilized. Control larvae $(N=5)$ were maintained on the gallic acid-free rearing diet. Control and gallic acid-containing diet $(25-30 \mathrm{mg})$ and frass $(5-30 \mathrm{mg})$ samples were extracted in $50 \%$ methanol $\left(3 \times 1.0 \mathrm{ml}, 50^{\circ} \mathrm{C}, 30 \mathrm{~min}\right)$ and analyzed for gallic acid using the rhodanine assay (Inoue and Hagerman, 1988) as described in Barbehenn and Martin (1992). The percent of ingested gallic acid remaining in the frass was calculated using the formula: (mg frass $\times \%$ GA in frass) $/ \mathrm{mg}$ ingested diet $\times \%$ GA in diet), with the amount of ingested diet calculated as above assuming an $\mathrm{AD}$ of $55.5 \%$.

Diet and frass samples collected for the measurement of a tannic acid budget (above) were also analyzed for gallic acid to determine the extent to which tannic acid was hydrolyzed by $M$. disstria. All samples were assayed for gallic acid using the rhodanine assay and a budget was calculated as described above.

Quantification of Phenol Oxidation. To compare the extent to which tannic acid is oxidized in larvae of $M$. disstria and $O$. leucostigma, the amount of brown pigment (oxidation products) that could be extracted from the frass of larvae consuming tannin-free and tannin-containing diets was determined. Finalinstar larvae were assigned at random to a control (tannin-free) diet $(N=24$ $M$. disstria, $N=10 O$. leucostigma) or tannin-containing ( $1 \%$ tannic acid) diet $(N=27 \mathrm{M}$. disstria, $N=10 \mathrm{O}$. leucostigma). Food and frass samples were collected and dried $\left(60^{\circ} \mathrm{C},>5\right.$ days) daily during the entire instar. After grinding with a mortar and pestle, 10 to $15 \mathrm{mg}$ subsamples were extracted in $70 \%$ acetone $\left(1.5 \mathrm{ml}, 50^{\circ} \mathrm{C}, 1 \mathrm{hr}\right)$ in a shaker. Samples were centrifuged $(13,500 \mathrm{~g}$, $5 \mathrm{~min}$ ) and the absorbance was measured with a Zeiss spectrophotometer (420 $\mathrm{nm})$ (Cilliers and Singleton, 1989). The background absorbance $\left(\mathrm{A}_{420} / \mathrm{mg}\right.$ sample) from each diet extract was subtracted from each frass extract to give a net 
production of brown pigment per milligram of frass. Means were compared by Mann-Whitney U-tests.

The fornation of brown pigments $\left(\mathrm{A}_{420} / \mathrm{mg}\right.$ sample) was also measured in frass of final-instar $M$. disstria larvae fed $2 \%$ gallic acid-containing diet. Methanolic extracts used for the measurement of gallic acid were diluted with $50 \%$ methanol $(3.5 \mathrm{ml})$, and the absorbance of each solution was measured with a spectrophotometer. Measurements of background absorbance in control and gallic acid-containing diets were made and used to correct levels of brown pigments extracted from frass. Measurements of $\mathrm{A}_{420}$ per milligram of frass were multiplied by 4.33 (dilution factor) to allow their comparison with measurements of tannic acid oxidation.

Gut Acid-Base and Redox Conditions. To compare the acid-base and redox conditions in the guts of $M$. disstria and $O$. leucostigma, $\mathrm{pH}$ and redox potentials were measured in the foreguts and midguts of larvae that had been chilled $\left(-20^{\circ} \mathrm{C}, 7 \mathrm{~min}\right)$ prior to dissection. $\mathrm{pH}$ was measured using a microneedle $\mathrm{pH}$ electrode (Microelectrodes MI-408P) and a silver-silver chloride reference electrode (Microelectrodes MI-401). Redox potentials were measured using a 0.02in. platinum electrode (Microelectrodes MI-800) and a silver-silver chloride reference electrode. To minimize exposure of the gut contents to air, the microelectrodes were inserted together through small adjacent holes cut through the gut wall. Because of the greater stability of the redox potential measurements, $\mathrm{pH}$ measurements were made first. All measurements were made using a Metrohm/Brinkman (model 103) millivolt and $\mathrm{pH}$ meter. Observed redox potentials were converted to standard redox potentials $\left(\mathrm{E}_{\mathrm{h}}\right)$ by adding $200 \mathrm{mV}$, and pe (electron availability) was calculated as $E_{h} / 59.2$ (Appel and Martin, 1990). Overall redox conditions were summarized by the "redox parameter" $(\mathrm{pH}+$ pe) (Appel and Martin, 1990).

\section{RESULTS}

In order to test the permeability of the peritrophic envelope of $M$. disstria to tannic acid, we fed larvae a diet containing tannic acid and tested for the presence of tannic acid in the incubating solutions surrounding excised guts in which small holes had been cut to expose the peritrophic envelope. A chromatogram of the tannic acid included in the larval diet is illustrated in Figure 1A. Commercial tannic acid is composed of galloyl esters of glucose along with some unesterified gallic acid. Peak a is gallic acid; peaks b-e are galloyl esters of glucose, which differ in the number of galloyl groups attached to the glucose moiety. None of the higher-molecular-weight components of tannic acid (peaks c-e) could be detected in the incubation solution after a 2-hr incubation period (Figure 1C). Indeed, chromatograms of incubating solutions surrounding the 


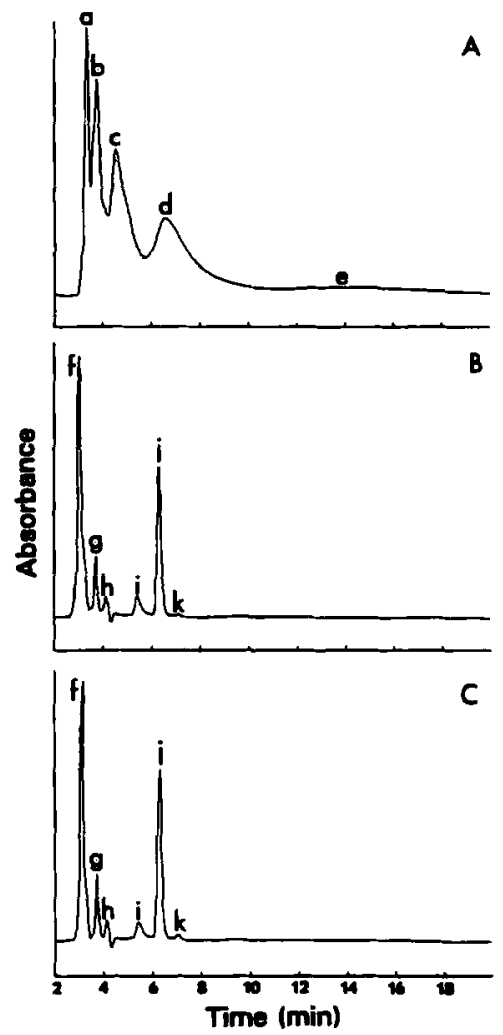

FIG. 1. Malacosoma disstria peritrophic envelope permeability to ingested tannic acid. (A) Chromatogram of tannic acid; (B) representative chromatogram of the incubating solution surrounding the gut of a larva fed a tannin-free diet $(N=3)$; (C) representative chromatogram of the incubating solution surrounding the gut of a larva fed a tannic acidcontaining diet $(N=11)$. No compounds eluted before $2 \mathrm{~min}$.

excised guts of larvae fed control (Figure 1B) and tannin-containing diets (Figure 1C) were virtually identical. The midguts of larvae fed the $3 \%$ tannic acid diet contained an average of $50 \mu \mathrm{g}$ of peaks $\mathrm{c}$ and $\mathrm{d}$ of tannic acid. The sensitivity of the analytical method was such that we could have detected $0.00125 \mu \mathrm{g}$ of tannic acid per microliter of incubating solution. Thus, we calculate that no more than $5 \%$ of the ingested tannic acid penetrated the peritrophic envelope during the 2-hr incubation period. Peaks f and $\mathrm{g}$ (Figure $1 \mathrm{C}$ ) include compounds in the incubation solution but could also include small amounts of gallic acid (peak a) and a low-molecular-weight polyphenol (peak b) from ingested tannic acid. 
This experiment was repeated using procedures that would ensure the presence of larger amounts of tannic acid in the midgut and the detection of smaller quantities in the incubating solution. When larvae were fed an $8 \%$ tannic acid diet, none of the polyphenols $\mathrm{c}$ or $\mathrm{d}$ could be detected in the incubating solutions, indicating that less than $0.3 \%$ of these polyphenols in the midgut penetrated the peritrophic envelope.

We quantified the amount of polyphenols $c$ and $d$ in tannic acid (Figure 1A) in the food and frass of $M$. disstria larvae to construct a tannic acid budget. Tannic acid was stable in the artificial diet; the efficiency of recovery of tannic acid from diet changed from virtually $100 \%$ soon after it was prepared to $94 \%$ after it was incubated for $24 \mathrm{hr}$ under the conditions of the feeding experiment. Of the ingested polyphenols, only $21 \%( \pm 2.4 \mathrm{SE})$ could be accounted for in the frass (Table 1). The remaining $79 \%$ was chemically transformed into substances that could not be detected using HPLC analysis.

The region of the digestive tract of $M$. disstria larvae in which the chemical transformation of tannic acid is most extensive was determined by a comparison of the percent of polyphenol d (Figure 1A) in the contents of the foregut, anterior midgut, posterior midgut, and hindgut (Table 2). There is a steady decrease in the percent of this tannic acid component as food passes from the foregut to the hindgut. Assuming that no food is assimilated from the foregut (Dow, 1986), but that $55.5 \%$ is assimilated during its passage through the midgut (Karowe, 1989), it can be calculated from the data summarized in Table 2 that only $29.0 \%$ of the tannic acid present in the food is still present in the posterior midgut (containing $0.27 \%$ polyphenol d). In the hindgut, only $18.7 \%$ of the tannic acid present in the food is still present (Table 1). These results clearly identify the midgut as the region in which the transformation of most of the tannic acid occurs.

Hydrolysis and oxidation are two chemical transformations that might reduce the levels of tannic acid in the guts of $M$. disstria. Although the measurement of gallic acid in the frass of an insect fed tannic acid might provide evidence for the hydrolysis of tannic acid, the amount of gallic acid present may be affected by either assimilation (Bemays et al., 1983; Kato, 1978) or oxidation (this study). Nonetheless, the results summarized in Table 1 suggest that hydrolysis accounts for the disappearance of only a small fraction of the tannic acid ingested by $M$. disstria. The tannic acid used in our experiments contained free gallic acid as an impurity (7\%). Given that the larvae, therefore, ingested 0.14 mg of free gallic acid and that the hydrolysis of pure tannic acid generates $70 \%$ of its weight in gallic acid, and assuming that gallic acid is assimilated or oxidized with an efficiency of $93.6 \%$ whether it is ingested or produced by hydrolysis, then the $0.012 \mathrm{mg}$ of gallic acid present in the frass can be accounted for by the hydrolysis of only $4 \%$ of the tannic acid ingested.

Phenol oxidation generates brown pigments (Hathway and Seakins, 1957; 


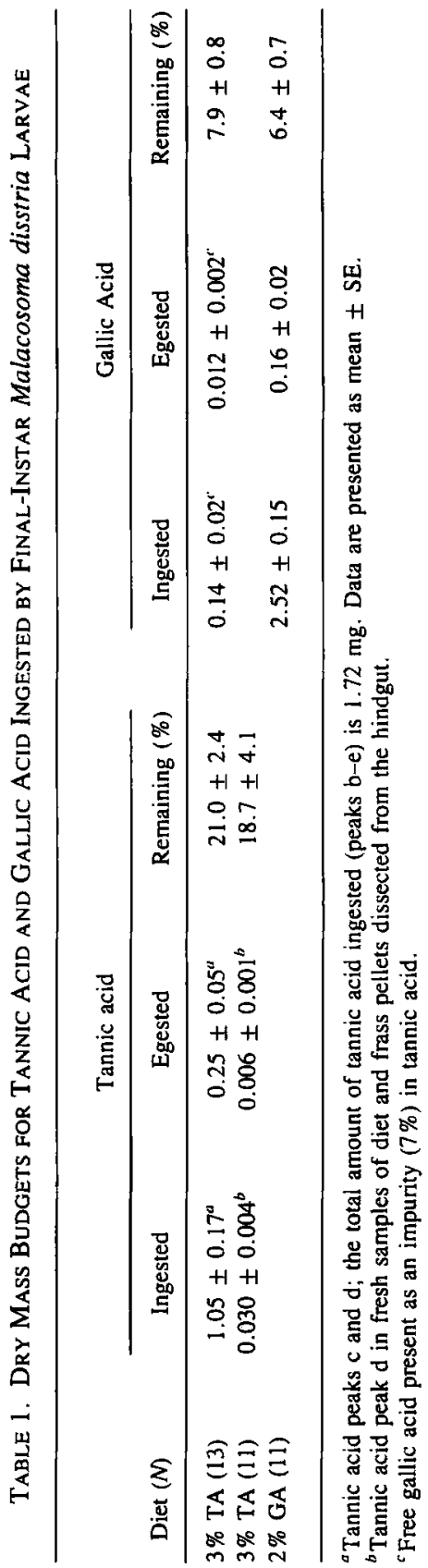


Thomson, 1962; Leatham et al., 1980; Igarashi and Yasui, 1985; Cilliers and Singleton, 1989). In $M$. disstria larvae fed a tannin-containing diet, the contents of the mid- and posterior midgut change from light tan to dark brown or greenbrown, suggesting the oxidation of tannins. Pigment formation in the guts of tannin-fed larvae was quantified by measuring the absorbance at $420 \mathrm{~nm}$ of extracts of the frass of $M$. disstria larvae fed tannin-free and tannin-containing artificial diets. The amount of brown pigment in the frass of $M$. disstria larvae fed a diet containing tannic acid is significantly greater $(P<0.0001)$ than the amount in the frass of larvae fed a tannin-free control diet (Figure 2). Brown pigments were present in larger amounts in the frass of male than of female

Table 2. Percent Tannic Acid in Diet and Guts of Final-Instar Malacosoma disstria LARVAE ${ }^{a}$

\begin{tabular}{ll}
\hline Sample location & $\begin{array}{c}\text { Percent } \\
\text { tannic acid }(N)\end{array}$ \\
\hline Artificial diet & $0.99 \pm 0.07(4)$ \\
Foregut & $0.86 \pm 0.08(11)$ \\
Anterior midgut & $0.80 \pm 0.11(11)$ \\
Posterior midgut & $0.64 \pm 0.09(11)$ \\
Hindgut & $0.42 \pm 0.09(11)$ \\
\hline
\end{tabular}

a Tannic acid component $d$ (Figure 1A). Data are presented as mean \pm SE.

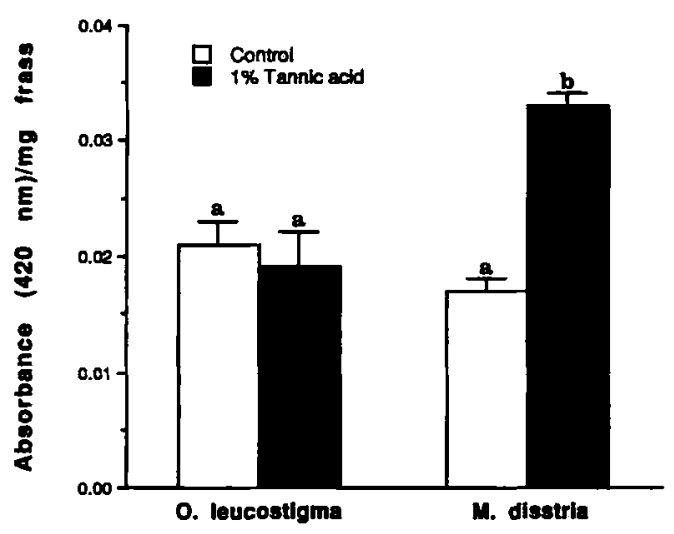

FIg. 2. Tannic acid oxidation in Malacosoma disstria (tannin sensitive) and Orgyia leucostigma (tannin tolerant). Data from male and female larvae are combined. Means within species were compared by Mann-Whitney U-tests. Different letters above bars denote $P<0.0001$. 
larvae fed both control $(P<0.0005)$ and tannic acid-containing $(P<0.0004)$ diets. Frass extracts from males and females fed control diets averaged 0.019 $\mathrm{AU} / \mathrm{mg}( \pm 0.001)$ and $0.014 \mathrm{AU} / \mathrm{mg}( \pm 0.001)$, respectively. Frass extracts from males and females fed tannic acid-containing diets averaged $0.036 \mathrm{AU} /$ $\mathrm{mg}( \pm 0.002)$ and $0.027 \mathrm{AU} / \mathrm{mg}( \pm 0.001)$, respectively. Ingested gallic acid was also oxidized by $M$. disstria larvae (Figure 3 ). Oxidation products (measured as absorbance at $420 \mathrm{~nm} / \mathrm{mg}$ frass) are elevated eightfold compared to control frass. These measurements cannot be used to calculate the actual amount of phenol oxidized, since the relationship between the amount of absorption at $420 \mathrm{~nm}$ by the pigments formed and the amount of phenol oxidized has not been determined.

The concentration of brown pigments that leached through the peritrophic envelopes of $M$. disstria larvae containing tannic acid was elevated twofold compared with their concentration in control solutions $(4200 \pm 230 \mathrm{AU} / \mu \mathrm{l}$ (mean $\pm \mathrm{SE}$ ) and $2220 \pm 70 \mathrm{AU} / \mu \mathrm{l}$, respectively). Most of the brown compounds eluted between 3.0 and $4.5 \mathrm{~min}$. However, the HPLC procedure we employed did not result in sufficient resolution of peaks to allow us to identify any new compounds generated during the oxidation of tannic acid.

In contrast to the production of brown pigments by $M$. disstria larvae fed a tannin-containing diet, when $O$. leucostigma larvae are fed a diet containing tannic acid their frass does not contain brown pigments in excess of those produced by larvae that consume a tannin-free diet (Figure 2). As noted earlier, tannic acid passes through the guts of $O$. leucostigma larvae without any chem-

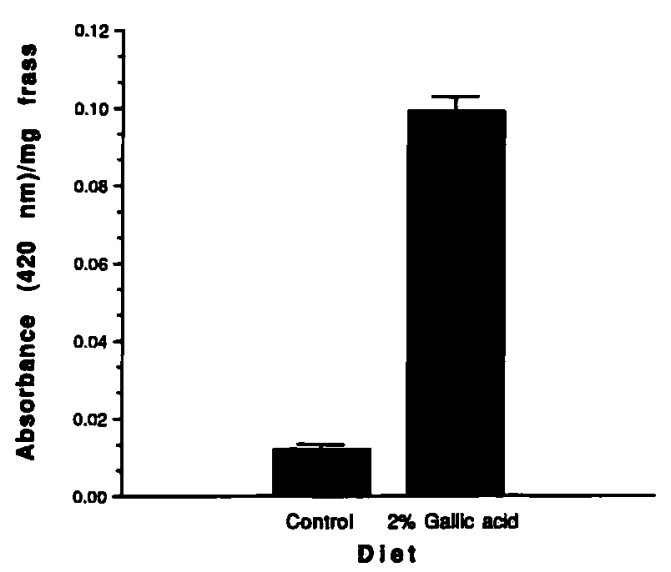

FIG. 3. Gallic acid oxidation in Malacosoma disstria larvae. Final-instar larvae were fed artificial diet containing $2 \%$ dry wt gallic acid or control diet. 
ical modification (Barbehenn and Martin, 1992). These experiments show that phenols are oxidized in the guts of $M$. disstria, but not in $O$. leucostigma.

In seeking an explanation for the occurrence of tannic acid oxidation in the guts of $M$. disstria larvae and the absence of oxidation in the guts of $O$. leucostigma larvae, we compared the redox conditions in their gut lumens. The $\mathrm{pH}$ and redox conditions in the guts of $M$. disstria and $O$. leucostigma are similar (Table 3). The midgut $\mathrm{pH}$ in both species is close to 10 , and as a consequence, ingested polyphenols are ionized. Likewise, the values of pe, a parameter that reflects electron availability (Lindsay, 1979; Appel and Martin, 1990), are similar in both the foreguts and midguts of the two species. As a consequence, the redox parameter $(\mathrm{pH}+\mathrm{pe})$, which is a composite measure of the redox status of a complex aqueous system giving equal weight to acid-base status and electron availability (Lindsay, 1979; Appel and Martin, 1990), is also similar in both species. $M$. disstria and $O$. leucostigma maintain weakly oxidizing conditions in their foreguts and strongly oxidizing conditions in their midguts. Thus, while these results are compatible with our observation of the occurrence of oxidation in the guts of $M$. disstria larvae, they provide no explanation for the absence of oxidation in $O$. leucostigma.

\section{DISCUSSION}

In this study we have demonstrated that the peritrophic envelope of the tannin-sensitive larvae of $M$. disstria, like the peritrophic envelope of the tannintolerant larvae of $O$. leucostigma, is impermeable to tannic acid. Clearly, the mere containment of tannic acid within the endoperitrophic space is insufficient to protect an insect herbivore from the potentially adverse effects of ingested tannins.

The impermeability of the peritrophic envelopes of $M$. disstria and $O$.

TABle 3. pH And Redox Conditions of Foreguts and Midguts of Malacosoma disstria AND Orgyia leucostigma ${ }^{a}$

\begin{tabular}{lcrrr}
\hline & $\mathrm{pH}$ & $\mathrm{Eh}(\mathrm{mV})$ & \multicolumn{1}{c}{$\mathrm{pe}$} & $\mathrm{pH}+\mathrm{pe}$ \\
\hline $\begin{array}{l}M \text {. disstria } \\
\text { Foregut }(\mathrm{n}=6)\end{array}$ & $6.06 \pm 0.10$ & $96 \pm 6$ & $1.61 \pm 0.11$ & $7.67 \pm 0.13$ \\
$\quad$ Midgut $(\mathrm{n}=10)$ & $10.23 \pm 0.07$ & $-30 \pm 12$ & $-0.51 \pm 0.21$ & $9.97 \pm 0.18$ \\
$\begin{array}{l}\text { O. leucostigma } \\
\text { Foregut }(\mathrm{n}=6)\end{array}$ & $5.58 \pm 0.27$ & $115 \pm 6$ & $1.94 \pm 0.11$ & $7.51 \pm 0.30$ \\
Midgut $(\mathrm{n}=14)$ & $9.80 \pm 0.11$ & $-3 \pm 11$ & $-0.05 \pm 0.19$ & $9.75 \pm 0.18$ \\
& & & & \\
\hline
\end{tabular}

${ }^{a}$ Data are presented as mean $\pm \mathrm{SE}$. 
leucostigma to the polyphenolic components of tannic acid presents an apparent dilemma, given that these molecules (approx. 3.5-4.7 nm diameter; Barbehenn and Martin, 1992) are smaller than the pore diameters in the peritrophic membranes of Lepidoptera, which have been reported to be greater than $7 \mathrm{~nm}$ (Adang and Spence, 1983; Santos and Terra, 1986; Wolfersberger et al., 1986). Two mechanisms might account for the containment of tannic acid within the endoperitrophic spaces of lepidopteran larvae: (1) binding by tannin-binding substances and (2) electrostatic exclusion. The binding of tannins by proteins or other substances (De Veau and Schultz, 1992; Ikeda et al., 1992) has the potential to form complexes with molecular dimensions that exceed the diameters of the pores of peritrophic membranes. Although the presence of tannin-binding proteins has not been examined in insects, they are produced by tannin-adapted vertebrate folivores (Austin et al., 1989). Secondly, the glycosaminoglycan component of the peritrophic membrane is ionized at physiological $\mathrm{pH}$, forming a dense, negatively charged barrier (Miller and Lehane, 1993). Phenolic hydroxyl groups would also be ionized under the strongly basic conditions that prevail in the midguts of $M$. disstria and $O$. leucostigma (Hagerman, 1989). It is possible that electrostatic repulsion between anionic sites in peritrophic membranes and negatively charged polyphenolate ions prevent the diffusion of polyphenols through the peritrophic envelope. The permeability of other extracellular matrices containing glycosaminoglycans has been found to be reduced for dextrans that bear negatively charged groups (Chang et al., 1975).

Our results provide support for the hypothesis that the primary determinant of the effect of ingested tannins on insect herbivores is their chemical transformation in the gut (Appel and Martin, 1990; Appel, 1993). The essential difference between the larvae of $M$. disstria and $O$. leucostigma that explains their tannin sensitivity and tannin tolerance, respectively, appears to be the occurrence of tannin oxidation in $M$. disstria. Whereas $90-100 \%$ of the tannic acid ingested by $O$. leucostigma is recoverable (Barbehenn and Martin, 1992), only 19-21\% of the tannic acid ingested by $M$. disstria can be recovered from the frass. Three observations suggest that tannic acid ingested by $M$. disstria is oxidized: (1) approximately $80 \%$ of ingested tannic acid is chemically transformed, (2) hydrolysis cannot account for the chemical modification of more than $4 \%$ of the ingested tannic acid, and (3) tannic acid and gallic acid produce brown pigments in the midguts of $M$. disstria, but not in $O$. leucostigma.

Our results do not support the hypothesis that thermodynamic indicators of gut redox conditions, such as the redox potential $\left(E_{h}\right)$ or the redox parameter (pe $\pm \mathrm{pH}$ ), are sufficient to predict the oxidation of phenols in lepidopteran larvae (Appel and Martin, 1990; Appel, 1993). Both M. disstria and O. leucostigma maintain strongly oxidizing redox conditions in their midguts, yet tannic acid is extensively oxidized in the former species but not in the latter. The thermodynamic favorability of oxidation (determined by oxidizing redox 
conditions) does not necessarily imply that oxidation is kinetically favorable, i.e., that phenol oxidation will proceed at an observable rate. The absence of phenol oxidation under conditions in which oxidation is favored thermodynamically could be explained by the absence of necessary catalysts (e.g., polyphenol oxidase, laccase) (Felton et al., 1989), the presence of antioxidant systems (e.g., catalase, dehydroascorbic acid reductase, ascorbic acid, $\alpha$-tocopherol) (Larson, 1988; Felton and Duffey, 1991, 1992; Summers and Felton, 1993) and/or low levels of essential oxidants (e.g., oxygen, hydrogen peroxide).

Although we are currently unable to distinguish among these potential mechanisms, we have made one observation consistent with the hypothesis that low oxygen levels in $O$. leucostigma may explain the absence of phenol oxidation in this species. The contents of the midguts of $O$. leucostigma, which are normally the same color as the diet (tan), turn dark brown in a few minutes after the gut is opened and its contents exposed to air. Oxygen tensions in the guts of insect herbivores have not been measured, to our knowledge. Such measurements might reveal important differences between tannin-sensitive and tannin-tolerant species.

The adverse effects of dietary tannic acid on $M$. disstria are different in early-and late-instar larvae. Early-instar larvae fed tannin-containing diets have low consumption rates, resulting in greatly prolonged development times and the failure to develop beyond the third or fourth instar (Karowe, personal communication; Barbehenn, unpublished). Feeding deterrence by polyphenols in early-instar lepidopteran larvae appears to be common (Isman and Duffey, 1982; Klocke and Chan, 1982; Manuwoto et al., 1985; Manuwoto and Scriber, 1986) and is even exhibited by early-instar larvae of the "tannin-tolerant" species $O$. leucostigma (Barbehenn, unpublished).

By contrast, when late-instar larvae of $M$. disstria are fed tannic acid, consumption and growth rates may be reduced, but little larval mortality occurs (Karowe, 1989). Instead, mortality occurs during the pupal stage and during the eclosion of adults (Karowe, 1989; Barbehenn, unpublished) and is associated with severe deformities in the wings of pupae and adults. Wings are commonly shortened to stubs in pupae (see Karowe, 1989) and are twisted and unexpanded in adults that are able to eclose. Similar wing deformities are the primary symptoms observed when many larval Lepidoptera are fed diets containing inadequate amounts of essential fatty acids (linolenic and/or linoleic acid) (Chippendale et al., 1964; Kato, 1978; Dadd, 1981). We hypothesize that since these polyunsaturated fatty acids are easily destroyed by oxidation (Lea, 1962), tannic acid acts as a prooxidant in $\boldsymbol{M}$. disstria, generating reactive radical oxidants (e.g., superoxide and hydroxyl radicals) that bring about the oxidation of essential fatty acids. We note that, in contrast to $M$. disstria, $O$. leucostigma larvae fed $M$. disstria diet containing 3\% tannic acid diet develop normal wings (Barbe- 
henn, unpublished). This result demonstrates the adequacy of the $M$. disstria diet for wing formation when the tannic acid remains unoxidized.

Wing deformities have also been observed when Spodoptera (Prodenia) eridania and Manduca sexta larvae are fed diets containing L-dopa or L-canavanine, respectively (Rehr et al., 1973; Rosenthal, 1977). In S. eridania, the wing deformities closely resemble those observed in $M$. disstria fed tannic acid. The authors postulated that L-dopa may interfere with tyrosinase, resulting in incomplete cuticle hardening and darkening. However, the observations reported Rehr et al. (1973) do not rule out the possibility that the adverse effects of ingested L-dopa are a consequence of its potential to act as a prooxidant that produces a deficiency in an oxidizable nutrient. Although our nutrient deficiency hypothesis remains untested, it is clear that the nature of the detrimental effect of tannins on late-instar $M$. disstria is different from that described previously in other tannin-sensitive insects, in which lesions in the midgut epithelium result in death during the feeding period (Bernays et al., 1980; Berenbaum, 1983; Steinly and Berenbaum, 1985).

Acknowledgments-This study was supported by NSF grant BSR-8904043 to M.M.M.

\section{REFERENCES}

ADANG, M.J., and SPENCE, K.D. 1983. Permeability of the peritrophic membrane of the Douglas fir tussock moth (Orgyia pseudotsugata). Comp. Biochem. Physiol. 75A:233-238.

ADDY, N.D. 1969. Rearing the forest tent caterpillar on an antificial diet. J. Econ. Entomol. 62:270271.

APPEL, H.M. 1993. Phenolics in ecological interactions: the importance of oxidation. J. Chem. Ecol. 19:1521-1552.

APPEL, H.M., and MARTIN, M.M. 1990. Gut redox conditions in herbivorous lepidopteran larvae. J. Chem. Ecol. 16:3277-3290.

Austin, P.J., Suchar, L.A., Robbins, C.T., and Hagerman, A.E. 1989. Tannin binding proteins in the saliva of deer and their absence in the saliva of sheep and cattle. J. Chem. Ecol. 15:13351347.

BarbehenN, R.V., and MARTIN, M.M. 1992. The protective role of the peritrophic membrane in the tannin-tolerant larvae of Orgyia leucostigma (Lepidoptera). J. Insect Physiol. 38:973-980.

Berenbaum, M. 1983. Effect of tannins on growth and digestion in two species of papilionids. Entomol. Exp. Appl. 34:245-250.

Bernays, E.A., Chamberlain, D., and McCarthy, P. 1980. The differential effects of ingested tannic acid on different species of Acridoidea. Entomol. Exp. Appl. 28:158-166.

Bernays, E.A., Chamberlain, D.J., and Woodhead, S. 1983. Phenols as nutrients for a phytophagous insect Anacridium melanorhodon. J. Insect Physiol. 29:535-539.

Chang, R.L.S., Deen, W.M., Robertson, C.R., and Brenner, B.M. 1975. Permselectivity of the glomerular capillary wall: III. Restricted transport of polyanions. Kidney Int. 8:212-218.

Chippendale, G.M., Beck, S.D., and STRONG, F.M. 1964. Methyl linolenate as an essential nutrient for the cabbage looper, Trichoplusia ni (Hübner). Nature 204:710-711.

Cilliers, J.J.L., and SinGLETON, V.L. 1989. Nonenzymic autoxidative phenolic browning reactions in a caffeic acid model system. J. Agric. Food Chem. 37:390-396. 
DADD, R.H. 1981. Essential fatty acids for mosquitoes, other insects and ventebrates, pp. 189-214, in G. Bhaskaran, S. Friedman, and J.G. Rodriguez (eds.). Current Topics in Insect Endocrinology and Nutrition. Plenum Press, New York.

DE VeAu, E.J.I., and SchULTZ, J.C. 1992. Reassessment of the interaction between gut detergents and phenolics in Lepidoptera and significance for gypsy moth larvae. J. Chem. Ecol. 18:14371453.

Dow, J.A.T. 1986. Insect midgut function. Adv. Insect Physiol. 19:188-328.

FEENY, P. 1968. Effect of oak leaf tannins on larval growth of the winter moth Operophtera brumata. J. Insect Physiol. 14:805-817.

FEENY, P. 1970. Seasonal changes in oak leaf tannins and nutrients as a cause of spring feeding by winter moth caterpillars. Ecology 51:565-581.

FeENY, P. 1976. Plant apparency and chemical defense, pp. 1-40, in J.W. Wallace and R.L. Mansell (eds.). Biochemical Interactions Between Plants and Insects. Plenum Press, New York.

FELTON, G.W., and DufFeY, S.S. 1991. Protective action of midgut catalase in lepidopteran larvae against oxidative plant defenses. J. Chem. Ecol. 17:1715-1732.

FELTON, G.W., and DufFeY, S.S. 1992. Ascorbate oxidation reduction in Helicoverpa zea as a scavenging system against dietary oxidants. Arch. Insect Biochem. Physiol. 19:27-37.

Felton, G.W., Donato, K., Del Vecchio, R.J., and Duffey, S.S. 1989. Activation of plant polyphenol oxidases by insect feeding reduces the nutritive quality of foliage for noctuid herbivores. J. Chem. Ecol. 15:2667-2694.

Hagerman, A.E. 1989. Chemistry of tannin-protein complexation, pp. 323-333, in R.W. Hemingway and J.J. Karchesy (eds.). Chemistry and Significance of Condensed Tannins. Plenum Publishing Corp., New York.

Hagerman, A.E., and Butler, L.G. 1991. Tannins and lignins, pp. 355-388, in G.A. Rosenthal and M.R. Berenbaum (eds.). Herbivores: Their Interactions with Secondary Plant Metabolites, 2nd ed., Vol. 1: The Chemical Participants. Academic Press, San Diego, Califomia.

Hathway, D.E., and SEakins, J.W.T. 1957. Autoxidation of polyphenols. Part 3. Autoxidation in neutral aqueous solution of flavans related to catechin. J. Chem. Soc. 2:1562-1566.

IGARASHI, K., and YASUI, T. 1985. Oxidation of free methionine and methionine residues in protein involved in the browning reaction of phenolic compounds. Agric. Biol. Chem. 49:2309-2315.

Ikeda, I., Imasato, Y., Sasaki, E., Nakayama, M., Nagao, H., Takeo, T., Yayabe, F., and SUGANO, M. 1992. Tea catechins decrease micellat solubility and intestinal absorption of cholesterol in rats. Biochim. Biophys. Acta 1127:141-146.

INOUE, K.H., and Hagerman, A.E. 1988. Determination of gallotannin with thodanine. Anal. Biochem. 169:363-369.

ISMAN, M.B., and DUFFEY, S.S. 1982. Toxicity of tomato phenolic compounds to the fruitworm, Heliothis zea. Entomol. Exp. Appl. 31:370-376.

KarOWE, D. 1989. Differential effect of tannic acid on two tree-feeding Lepidoptera: Implications for theories of plant-herbivore chemistry. Oecologia 80:507-512.

Kato, M. 1978. Phenols as indispensible components of the synthetic diet of the silkworm, Bombyx mori. Entomol. Exp. Appl. 24:284-290.

KLOCKE, J.A., and CHAN, B.G. 1982. Effects of cotton condensed tannin on feeding and digestion in the cotton pest, Heliothis zea. J. Insect Physiol. 28:911-915.

LARSON, R.A. 1988. The antioxidants of higher plants. Phytochemistry 27:969-978.

LEA, C.H. 1962. The oxidative deterioration of food lipids, pp. 3-28, in H.W. Schultz (ed.). Symposium in Foods: Lipids and their Oxidation. Avi Publishing, Westport, Connecticut.

LEATHAM, G.F., KING, V., and StAhMANN, M.A. 1980. In vitro protein polymerization by quinones or free radicals generated by plant or fungal oxidative enzymes. Phytopathology 70:11341140.

LINDSAY, W.L. 1979. Chemical Equilibria in Soils. John Wiley \& Sons, New York. 
MANuwoto, S., and SCRiber, J.M. 1986. Effects of hydrolyzable and condensed tannin on growth and development of two species of polyphagous Lepidoptera: Spodoptera eridania and Callosamia promethea. Oecologia 69:225-230.

Manuwoto, S., Scriber, J.M., Hsia, M.T., and Sunarjo, P. 1985. Antibiosis/antixenosis in tulip tree and quaking aspen leaves against the polyphagous southern armyworm, Spodoptera eridania. Oecologia 67:1-7.

Miller, N., and Lehane, M.J. 1993. Ionic environment and the permeability properties of the peritrophic membrane of Glossina morsitans morsitans. J. Insect Physiol. 39:139-144.

ReHR, S.S., JANZEN, D.H., and FeEny, P.P. 1973. L-Dopa in legume seeds: A chemical barrier to insect attack. Science 181:81-82.

RHOADES, D.F., and CATES, R.G. 1976. Toward a general theory of plant antiherbivore chemistry. Recent Adv. Phytochem. 10:168-213.

RosentHAL, G.A. 1977. The biological effects and mode of action of L-canavanine, a structural analogue of L-arginine. Q. Rev. Biol, 52:155-178.

SANTOS, C.D., and TERRA, W.R. 1986. Distribution and characterization of oligomeric digestive enzymes from Erinnyis ello larvae and inferences conceming secretory mechanisms and the permeability of the peritrophic membrane. Insect Biochem. 16:691-700.

SCHUL.TZ, J.C. 1989. Tannin-insect interactions, pp. 417-433, in R.W. Hemingway and J.J. Karchesy (eds.). Chemistry and Significance of Condensed Tannins. Plenum Press, New York.

STEHR, F.W., and Cook, E.F. 1968. A revision of the genus Malacosoma Hübner in North Americana (Lepidoptera: Lasiocampidae): Systematics, biology, immatures, and parasites. Smithsonian Institution Press, Washington, D.C.

Steinly, B.A., and Berenbaum, M. 1985. Histopathological effects of tannins on the midgut epithelium of Papilio polyxenes and Papilio glaucus. Entomol. Exp. Appl. 39:3-9.

Summers, C.B., and Felton, F.W. 1993. Antioxidant role of dehydroascorbic acid reductase in insects. Biochim. Biophys. Acta 1156:235-238.

ThOMSON, R.H. 1962. Some naturally occurring black pigments, pp. 99-113, in T.S. Gore, B.S. Joshi, S.V. Sunthankar, and B.D. Tilak (eds.). Recent Progress in the Chemistry of Natural and Synthetic Colouring Matters and Related Fields. Academic Press, New York.

Wolfersberger, M.G., SPAeth, D.D., and Dow, J.A.T. 1986. Permeability of the peritrophic membrane of tobacco hornworm larval midgut. Am. Zool. 26:74A. 